\title{
Study on Prescribing Pattern of Antibiotics in a Pediatric Out-Patient Department in a Tertiary Care Teaching and Non-Teaching Hospital
}

\author{
Ashok Kumar Malpani ${ }^{* 1}$, Manjunath Waggi', Asmila Rajbhandari ${ }^{2}$, Gunda Anil Kumar ${ }^{2}$, Reddy Nikitha $^{2}$, \\ Alapathy Kalyan Chakravarthy²
}

1'Department of Pharmacy Practice, RMES's College of Pharmacy Old Jewargi Road Gulbarga, Karnataka-585102, INDIA.

2Department of Pharmacy Practice, NET Pharmacy College, NMCH\&RC, Mantralayam Road, Raichur, Karnataka-584103, INDIA.

\begin{abstract}
Aim: The aim of the study is to conduct a prospective study on prescribing pattern of antibiotics in the out-patient department of Pediatrics and to evaluate the rational use of antibiotics. Methods: The study was conducted with a sample size of 480 patients for a period of 6 months at a Tertiary Care Teaching and Non-teaching Hospital after taking consent from both the hospitals. Results: In our study, a total of 480 prescriptions, hospital 1:225/129 and hospital 2: 225/154 were screened. Out of which $129(57.3 \%)$ and $154(60.39 \%)$ contained antibiotics and the average number of drugs was $2.93 \pm 0.96$ and $2.94 \pm 0.9$ for hospital 1 and 2 respectively. Majority of the prescriptions contained only one antibiotic. Moderate drug interactions of $85 \%$ and minor interactions of $15 \%$ were found from both the hospitals. Most common diseases found were upper respiratory tract infections (URTI-25.58\%), fever (25.58\%), gastroenteritis (GE) $17.82 \%)$ in hospital 1 and fever $(22.72 \%)$, URTI (20.12\%), LRTI (14.93\%), GE (19.48) and UTI (16.23\%) in hospital-2.Commonly prescribed antibiotic class and drugs was penicillin-amoxicillin(18.18\%)-hospital1,cephalosporins-cefixime(32.14\%), ceftriaxone (21.42\%) and cefodoxamine (40.17\%)-hospital 2 . The commonly used antibiotic combination was amoxicillin + clavulanic acid (hospital1:75\%, hospital2-100\%). The average total prescription cost and antibiotic cost was Rs. 96.96 and Rs. 45.30 (hospital 1), and Rs. 69.80\&Rs. 39.60. (hospital 2) respectively. Conclusion: The total number of drugs and the number of antibiotics prescribed were found to be rational in both the hospitals. However more rationality was observed in non-teaching hospital with regard to prescribing pattern as well as economic criteria compared to teaching hospital.
\end{abstract}

Key words: Prescribing pattern, Antibiotic, Outpatient, Paediatric.

\section{INTRODUCTION}

Paediatrics is the branch of medicine dealing with the development, diseases and disorders of children. Infancy and childhood is a period of rapid growth and development. Drug therapy is considered to be major component of paediatric management in health care setting like hospital. ${ }^{1}$ Many infectious diseases have been controlled in 20th century by improving living conditions, public health measures and with the use of antimicrobial agents (AMAs). Antibiotics are the key drugs for treatment of infections and are among the most commonly prescribed drugs in paediatrics department. ${ }^{2}$ Their indiscriminate use increases the risk of bacterial drug resistance and thus have prompted the need to use antibiotics judiciously in paediatrics practice. ${ }^{3}$ Many of the antibiotics are unnecessarily prescribed for viral infections such as common cold. ${ }^{4}$ Thus using antibiotics to treat these viral infections is considered misuse/overuse of antibiotics. According to the national ambulatory medical care survey (NAMCS), antibiotics are the second leading drug which is being prescribed or considered for treating infectious disease in children. ${ }^{5-7}$ Therefore, a proper selection of antibiotics along with prescribing of appropriate dose, formulation, pharmacokinetics profiles, response, and adverse drug reactions (ADRs) must be considered very
DOI: 10.5530/ijopp.9.4.7

Address for correspondence: Prof. Dr Ashok Kumar Malpani,

RMES's College of Pharmacy Old Jewargi Road Gulbarga,

Karnataka-585102, INDIA.

Phone no: 9845407765

E-mail: malpani_ashok@ rediffmail.com

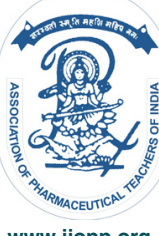

www.ijopp.org 
seriously otherwise they may lead to fatal effects and promote the spread of antibiotics resistance. ${ }^{8,9}$ Nowadays many paediatric physicians are including antibiotics in their prescriptions as an empirical therapy without considering whether it is rational or not. The irrational use of antibiotics is leading to destruction of microflora, emergence of multi drug resistant microorganisms, and clinical symptoms like toxic megacolon and pseudo membranous colitis. All these are responsible for serious infections in the outpatients. This irrational use has lead to the development of "super bugs", use of more combination of antibiotics and fearing the experts about future availability of antibiotics therefore, an effective step should be taken for rational use, especially in the paediatric population. ${ }^{10}$

To overcome the above problems and to assure safe and cost effective therapy, antibiotic guidelines are required in a hospital setup. By definition, "Antibiotic guidelines are standard set of guidelines for the treatment of infectious diseases based on local culture sensitivity data.". ${ }^{11}$

The ultimate goal of this study is to achieve rational and cost-effective medical care, particularly in the economically developing countries. Hence the present study was carried out to know the outpatient prescribing pattern in paediatric patients of a teaching and non-teaching hospital (hospital 1 and hospital 2, respectively).

\section{MATERIALS AND METHODS}

An institutional research ethical clearance was obtained. STUDY DESIGN: Prospective observational study. STUDY SITE: Pediatric department of tertiary care teaching

Hospital and non-teaching hospital.

STUDY DURATION: 6 months.

INCLUSION CRITERIA: patients of either sex within the age group of 1 to 16 Years from pediatric department of teaching\& non- teaching hospital.

EXCLUSION CRITERIA: All the In-patients from wards and PICU/NICU

SOURCE OF DATA: Patient data relevant to the study was obtained from prescription and direct interview.

SAMPLE SIZE: 480

Study procedure: prescriptions of outpatients were reviewed prospectively for antibiotics in the paediatric departments of a teaching and non-teaching hospital (hospital 1 and hospital 2, respectively).

\section{Determination of prescription pattern}

In both the hospitals, prescriptions were analyzed for the most commonly used antibiotics and its category, indication, rationality of the prescription (number of antibiotics prescribed, appropriateness of dose $\&$ drug interactions (DIs)).

Pharmacoeconomic evaluation like total cost of each prescription and antibiotics cost was calculated by using latest editions of tertiary sources and direct interaction with community / hospital pharmacy/ patients.

Statistical analysis: Descriptive statistical analysis has been carried out in the present study.

\section{RESULTS}

A total of 480 outpatient prescriptions (hospital 1: 225/129 and hospital 2: 255/154) were screened from the two hospitals (a teaching and non-teaching hospital). In the teaching hospital, a total of 225 prescriptions were screened, out of which only 129 prescriptions contained antibiotics and whose patients accepted to give the assent/consent. Whereas in the non-teaching hospital, out of 255 prescriptions, only 154 contained antibiotics and whose patients accepted to give the assent/ consent. A total of 283 prescriptions were assessed in the teaching and nonteachinghospital.

The percentage of patients was $45.58 \%$ (129) and $54.41 \%$ (154) in the teaching and non-teaching hospital, respectively. In the teaching hospital, the percentage of male patients was $45.73 \%$ (59) and in non-teaching paediatric hospital, $58.4 \%(90)$. The percentage of female patient was found to be more in the teaching hospital 54.26\%(70)compared to non-teaching hospital it was $41.5 \%(64)$. (Figure 1 ).

In the teaching hospital, the number of patients aged less than 1 year is 10 and the same in non-teaching hospital is 54 . The number of patients aged between 1-4 years in the teaching hospital is 78 and the same in the nonteaching hospital is 76 . Interestingly, at the age of more than 4-8 years, the paediatric patients show an equal or slightly higher number. In the teaching hospital, 17 and 04patients were assessed in the age group of 8-12 and 12-16 years. However, there were no patient of the same age group in the non-teaching hospital. (Table 1).

The number of prescriptions containing single drug was found to be 02 in hospital 1, whereas none of such kind was found in the non-teaching hospital. the number of prescriptions containing 2 drugs was found to be 37 in hospital 1 whereas 68 in hospital 2. The 3 drug containing prescriptions was found to be more in hospital 1 i.e; 62 compared to hospital 2(57). Whereas 4 and 5 drug containing prescriptions in hospital 1 is 18 and 08 respectively, in hospital 2 it was found to be 24 and 03 respectively. Interestingly, 6 drug containing prescriptions was found to be 0 in case of hospital 1 whereas 
in hospital 2 it is found to be 02 And 7 drug containing prescriptions was found to be almost same in both hospitals(hospital 1:2,hospital 2: 2 respectively). (Table 2).

In the study population, infectious diseases like URTI, LRTI, fever were most prominent diagnosis found in both the hospitals[hospital 1: 76(58.91\%) \& hospital 2:89(57.79\%)].It is followed by other manifestations like Acute GE,UTI in both the hospiatls [hospital 1: (33.33\%), hospital 2:55(35.71\%)]. Whereas other diagnoses made comprised hospital 2:6.49\% hospital 1: $11.62 \%$.( Table 3 )

In our study the mainly prescribed antibiotics in the both the hospitals were:

Cephalosporins (hospital 1:33.33\%, hospital 2:34.14\%), Penicillin (hospital 1:34.10\%, hospital 2:39.02), Macrolides (hospital1:24.03\%, hospital2 :4.26\%) Aminoglycosides (hospital1:1.55\%, hospital2 :6.09\%), Quinolones (hospital 1:6.97\%,hospital2:15.85\%). (Table 4)

In our study among the prescribed antibiotics the commonly prescribed cephalosporins were: ceftriaxone $(7.31 \%, 2.32 \%)$, Cefotaxime $(0 \%, 9.3 \%)$, Cefadroxil (0\%, 8.52\%), Cefixime(10.97\%,5.42\%) Cefpodoxime (14.02\%, 5.42\%), Cefpodoxime (0\%, 2.32\%), and

Cefuroxime $(1.82 \%, 0 \%)$ in hospital 2 and hospital 1 respectively. (Table 5)

Among Penicillins, ampicillin+clavulanic acid has been commonly prescribed in both the hospitals (hosp1:25.5\%,hosp-2:39.02\%), whereas amoxicillin (6.21\%) and ampicillin (2.32\%) have been less commonly prescribed in hospital 1 and none of them have been prescribed in hospital 2.

Among the prescribed Macrolide antibiotics, Azithromycin was only choice of drug in our study population in both the hospitals. (Table 6)



Figure 1: Gender distribution of Study population.
In Fluoroquinolones, ofloxacin was commonly prescribed to the patients in both the hospitals (hosp 2:15.85\%,hosp 1:3.10\%). The others quinolones such as norfloxacin $(0.77 \%)$ levofloxacin $(0.77 \%)$ and ciprofloxacin $(2.32 \%)$ were given in hospital 1 .

In Aminoglycosides, Gentamicin was more recommended in hosp $2(6.09 \%)$ than in hosp 1(1.55\%).

The prescriptions containing two or more drugs were for supportive treatment. The various supportive drugs being used in hosp1 and hosp 2 were paracetamol 63 (48.8\%),94 (61.03\%), cough syrups $32(24.8 \%), 13$ (8.4\%); multivitamins 20 (15.5\%),8 (5.1\%). The other supportive drugs that were being used were antihistamines (hosp 1: 36(29.4\%), hosp2: 10(6.49\%)).(Table 7)

In our study amoxicillin+clavulanic acid was commonly prescribed for respiratory infections and fever in both the hospitals followed by cephalosporins. Azithromycin was prescribed for few respiratory infections and for fever. Quinolones are commonly prescribed for Urinary tract infection and other infections in both the hospitals. (Table 8)

In our study, $84.61 \%$ moderate $\& 15.38 \%$ minor Drug interaction were found. (Figure 2)

The minor Drug interactions were with Ampicillin and Azithromycin \& Moderate interactions were with Gentamicin and ceftriaxone, Cefotaxime and Gentamicin, Quinolones and Azithromycin, Ampicillin and Gentamicin, Quinolones and Multivitamins.

The total and average prescription cost of hospital 1 was Rs 12,508.14 and Rs. 96.96 respectively. The total antibiotic cost was calculated as Rs. 5844.44 and the average of antibiotic cost as Rs. 45. Whereas in the hospital 2 the total and average prescription cost was Rs. 10,750.33 and Rs. 69.80. 30. The total antibiotic cost was calcu-

\section{Drug Interactions}

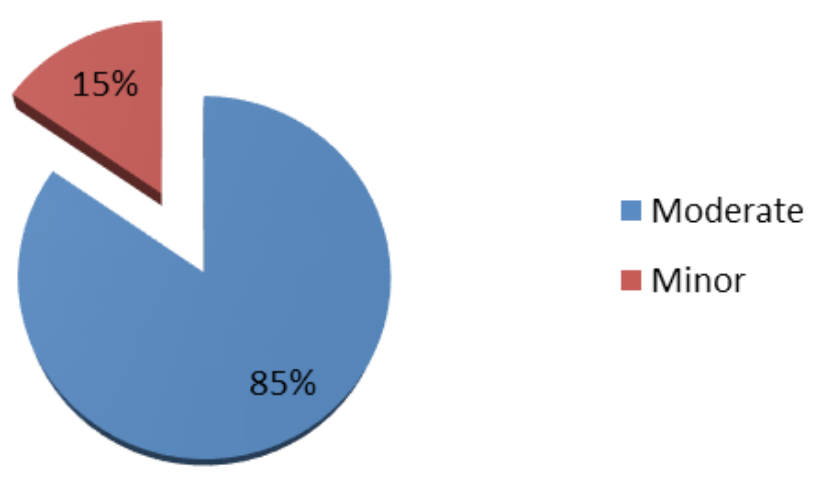

Figure 2: Drug Interactions noted in the Study population. 


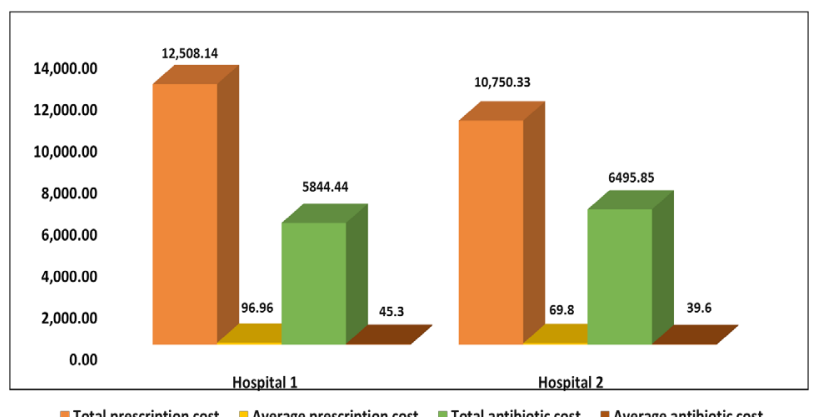

Table 1: Age Distribution of Study population

Figure 3: Distribution of costs of prescriptions in two hospitals.

\begin{tabular}{ccccc}
$\begin{array}{c}\text { AGE } \\
\text { (YEARS) }\end{array}$ & $\begin{array}{c}\text { HOSPITAL } \\
\mathbf{1}\end{array}$ & $\mathbf{\%}$ & $\begin{array}{c}\text { HOSPITAL } \\
\mathbf{2}\end{array}$ & $\%$ \\
\hline$<1 \mathrm{yr}$ & 10 & 7.75 & 54 & 35.06 \\
1-4 yrs & 78 & 60.4 & 76 & 49.35 \\
$4-8 \mathrm{yrs}$ & 20 & 15.5 & 24 & 15.58 \\
8-12 yrs & 17 & 13.1 & 00 & 00 \\
12-16yrs & 04 & 3.1 & 00 & 00 \\
TOTAL & $\mathbf{1 2 9}$ & $\mathbf{1 0 0}$ & $\mathbf{1 5 4}$ & $\mathbf{1 0 0}$ \\
\hline
\end{tabular}

Table 2: Distribution pattern of total number of drugs in the outpatient prescriptions

\begin{tabular}{ccccc}
\hline $\begin{array}{c}\text { Total number of drugs in the } \\
\text { prescription }\end{array}$ & Hospital $\mathbf{1}(\mathbf{N})$ & $\%$ & Hospital $\mathbf{2}(\mathbf{N})$ & \% \\
\hline 1 & 2 & 1.5 & 0 & 0 \\
2 & 37 & 28.6 & 68 & 44.15 \\
3 & 62 & 48.06 & 57 & 37.01 \\
4 & 18 & 13.9 & 24 & 15.5 \\
5 & 8 & 6.20 & 03 & 1.94 \\
6 & 0 & 1.5 & 02 & 1.2 \\
7 & 2 & 100 & $\mathbf{1 5 4}$ & 1.2 \\
Total & $\mathbf{1 2 9}$ & & $\mathbf{2 . 9 4} \pm \mathbf{0 . 9}$ & $\mathbf{1 0 0}$ \\
Mean SD & $\mathbf{2 . 9 3} \mathbf{0 . 9 6}$ & &
\end{tabular}

\begin{tabular}{ccccc}
\hline $\begin{array}{c}\text { Table 3: Details on distribution pattern of outpatient's disease } \\
\begin{array}{c}\text { Disease } \\
\text { diagnosed }\end{array}\end{array}$ & $\begin{array}{c}\text { Hospital } \mathbf{1} \\
\text { (N) }\end{array}$ & $\%$ & $\begin{array}{c}\text { Hospital 2 } \\
\text { (N) }\end{array}$ & $\%$ \\
\hline LRTI & 10 & 7.75 & 23 & 14.93 \\
URTI & 33 & 25.58 & 31 & 20.12 \\
Fever & 33 & 25.58 & 35 & 22.72 \\
Pharyngitis & 00 & 00 & 00 & 00 \\
Pneumonia & 00 & 00 & 00 & 00 \\
Acute GE & 23 & 17.82 & 30 & 19.48 \\
UTI & 20 & 15.50 & 25 & 16.23 \\
Others & 15 & 11.62 & 10 & 6.49 \\
TOTAL & $\mathbf{1 2 9}$ & $\mathbf{1 0 0}$ & $\mathbf{1 5 4}$ & $\mathbf{1 0 0}$ \\
\hline
\end{tabular}

\begin{tabular}{rccccc}
\multicolumn{2}{c}{ Table 4:Antibiotics prescribed to the Study Population } & & & \\
\hline S.NO & ANTIBIOTICS & HOSPITAL 1 & $\%$ & HOSPITAL 2 & (\%) \\
\hline 1. & Cephalosporins & 43 & 33.33 & 56 & 34.14 \\
2. & Penicillins & 44 & 34.10 & 64 & 39.02 \\
3. & Fluoroquinolones & 09 & 6.97 & 26 & 15.85 \\
4. & Macrolides & 31 & 24.03 & 07 & 4.26 \\
5. & Aminoglycosides & 02 & 1.55 & 10 & 6.09 \\
6. & TOTAL & 129 & 100 & 164 & 100 \\
\hline
\end{tabular}




\begin{tabular}{|c|c|c|c|c|c|}
\hline S.NO & CEPHALOSPORINS & HOSPITAL 1 & $\%$ & HOSPITAL 2 & $(\%)$ \\
\hline 1. & Ceftriaxone & 03 & 6.97 & 12 & 21.42 \\
\hline 2. & Cefotaxime & 12 & 27.9 & 00 & 00 \\
\hline 3. & Cefadroxil & 11 & 25.5 & 00 & 00 \\
\hline 4. & Cefixime & 07 & 16.2 & 18 & 32.14 \\
\hline 5. & Cefpodoxamine & 07 & 16.2 & 23 & 41.07 \\
\hline 6. & Cefodoxime & 03 & 6.97 & 00 & 00 \\
\hline 7. & Cefuroxime & 00 & 00 & 03 & 5.35 \\
\hline
\end{tabular}

\begin{tabular}{|c|c|c|c|c|c|}
\hline S.NO & PENICILLINS & HOSPITAL 1 & $\%$ & HOSPITAL 2 & (\%) \\
\hline 1. & Amoxicillin & 08 & 18.18 & 00 & 00 \\
\hline 2. & Ampicillin & 03 & 6.81 & 00 & 00 \\
\hline 3. & Amoxicillin+clavulanic acid & 33 & 75 & 64 & 100 \\
\hline
\end{tabular}

Table 7: Concurrent drugs prescribed in Study population

\begin{tabular}{cccccc} 
SNO & $\begin{array}{c}\text { CONCURRENT DRUGS } \\
\text { PRESCRIBED }\end{array}$ & HOSPITAL 1 & \% & HOSPITAL 2 & \% \\
\hline 1. & Paracetamol & 63 & 48.8 & 94 & 61.03 \\
2. & Cough syrups & 32 & 24.84 & 13 & 8.4 \\
3. & multivitamins & 20 & 15.5 & 8 & 5.1 \\
4. & Antihistamines & 36 & 29.4 & 10 & 6.49 \\
\hline
\end{tabular}

\section{Table 8: Distribution pattern of type of antibiotics used for specific disease in} Hospital 1 and Hospital 2

\begin{tabular}{|c|c|c|c|c|c|c|c|c|c|c|c|c|c|c|}
\hline \multicolumn{15}{|c|}{ HOSPITAL 1} \\
\hline $\begin{array}{c}\text { Disease } \\
\text { Diagnosed }\end{array}$ & Amox & Amp & Cef & Cefo & Cefa & Cefi & Cefpo & Cefd & cefu & Quino & Mac & Genta & $A+C$ & Total \\
\hline LRTI & - & - & 01 & - & 02 & - & - & - & - & - & - & - & 03 & 06 \\
\hline URTI & 08 & 03 & 02 & 05 & - & - & 05 & - & - & - & 10 & - & 09 & 42 \\
\hline Fever & - & - & - & 07 & 06 & 07 & 02 & 03 & - & - & 08 & - & 09 & 47 \\
\hline Acute GE & - & - & - & - & 03 & - & - & - & - & 03 & - & - & 07 & 13 \\
\hline UTI & - & - & - & - & - & - & - & - & - & 06 & 03 & - & - & 09 \\
\hline Others & - & - & - & - & - & - & - & - & - & - & 10 & 02 & - & 12 \\
\hline Total & 08 & 03 & 03 & 12 & 11 & 07 & 07 & 03 & 00 & 09 & 31 & 02 & 33 & 129 \\
\hline \multicolumn{15}{|c|}{ HOSPITAL 2} \\
\hline $\begin{array}{c}\text { Disease } \\
\text { Diagnosed }\end{array}$ & Amox & Amp & Cef & Cefo & Cefa & Cefi & Cefpo & Cefd & cefu & Quino & Mac & Genta & $A+C$ & Total \\
\hline LRTI & - & - & 02 & 05 & - & - & 07 & - & 03 & - & 02 & - & 12 & 29 \\
\hline URTI & - & - & 02 & - & - & - & - & - & - & - & 05 & - & 15 & 22 \\
\hline Fever & - & - & 06 & 10 & - & - & 13 & - & - & - & - & - & 12 & 43 \\
\hline Acute GE & - & - & - & - & - & - & - & - & - & - & - & - & 05 & 05 \\
\hline UTI & - & - & - & - & - & - & - & - & - & 17 & - & - & 06 & 23 \\
\hline Others & - & - & 02 & 03 & - & - & 03 & - & - & 09 & - & 10 & 15 & 42 \\
\hline Total & 00 & 00 & 12 & 18 & 00 & 00 & 23 & 00 & 03 & 26 & 07 & 10 & 64 & 164 \\
\hline
\end{tabular}


lated as Rs. 6495.85 and the average of antibiotic cost as Rs. 39.60. (Figure 3)

\section{DISCUSSION}

In our study, a total of 283 prescriptions containing antibiotics were recorded from a total of 480 prescriptions collected from both the hospitals. Male paediatric patients were more in hospital 2 (58.4\%) when compared to female $(41.5 \%)$, where as in hospital 1 the female $(45.73 \%)$ paediatric patients were more when compared to males $(45.73 \%)$. Similar results were found in the studies conducted by Palikhe ${ }^{1}$ (males $61.9 \%$ and female $38.1 \%$ ) and Kolar and Hromadova ${ }^{12}$ (males $58.2 \%$ and females $48.1 \%$ ).

In both the hospitals, more number of patients belonged to the age group of 1-4 years (hosp 1:60.4\%, hosp 2: $49.35 \%)$. This is very natural because in this age, the children's attitude will be more and immune power will be less. Less percentages were observed in the children of age group 4-8 years (hosp 1:15.5\%, hosp 2:15.58\%). Interestingly in the hospital $2(0 \%)$, children of the age group 8-16 years, the number of disease occurrence was less when compared to hospital $1(16.2 \%)$. The mean age group in the study in hospital 1 is $4.04 \mathrm{yrs}$ and in hospital 2 is 2.25 yrs. Compared mean age group 7.5 years study conducted by Kolar and Hromadova. ${ }^{12}$

More number of prescriptions contained 2 and 3 drugs in both the hospitals (hospital1 :( 28.6\%, \& 48.06\%), hospital $2:(44.15 \%$, \& 37.01\%). The other study conducted by Ashraf ${ }^{6} \&$ Sunil Mathur ${ }^{13}$ shown the average number of drugs per prescription was found to be 3.46 and 3.59 respectively.

In both the hospitals, these prescriptions generally contained supplementary drugs along with only one antibiotic (two drugs in rare cases). The percentage of supplementary drugs was more for paracetamol (hosp 1:48.8\%, hosp 2:61.3\%) followed by cough syrups (hosp1:24.84\%, hosp2:8.4\%) \& multivitamin (hosp1:15.5\% hosp2:5.1\%). The percentage of antihistamines as supplementary drug was more in hospital $1(29.1 \%)$ when compared to hospital $2(6.49 \%)$. This showed that the hospital 2 was more concerned about the need of drug utilization and economic conditions when compared to hospital 2.

In hospital 2, the most widely prescribed class of antibiotics for the paediatric patients was penicillin-amox icillin+clavulanicacid $(100 \%)$, followed by cefpodoxime (41.07\%), cefixime $(32.14 \%)$, ceftriaxone $(21.42 \%)$, $\&$ cefuroxime $(5.35 \%)$. Whereas in hospital-1 it was amoxicillin+clavulanicacid $(75 \%)$, penicillin-amoxicillin(18.18), ampicillin(6.81\%).Cephalosporins: cefotaxim (27.9\%), and cefadroxil (25.5\%),cefixime
(16.2\%), cefpodoxime (16.2\%)ceftriaxone (6.97\%). Antibiotics belonging to Penicillin class were found to be commonly used according to the studies conducted by Sunil Mathur et al. ${ }^{13}(23.82 \%)$, Mohan et al., ${ }^{14}$ (86.4\%), Palcevski et al. ${ }^{15}(28.96 \%)$ and Most of the patients under this study category suffered from respiratory tract infections for which amoxicillin is the drug of choice as per the Centre for Disease Control and Prevention (CDC) recommendations.

In the hospital 2 more number of fever $(22.72 \%)$ cases were found, followed by URTI $(20.12 \%)$ and LRTI (14.93\%). Whereas in hospital 1 fever $(22.58$ $\%)$ and URTI (25.58\%) were more commonly found followed by LRTI $(7.75 \% 5)$. Whereas UTI cases were more in hospital 2(16.23\%) when compared to hospital $1(15.50 \%)$. The paediatric population is more exposed to respiratory diseases, because the occupation of their parents is agriculture or because of air pollution. Occurrence of fever was almost same in both the hospitals which may be because of food or air contamination. Similar results, for LRTI(29.28\%) was found in the study conducted by Sharma et al. ${ }^{16}$

In both the hospitals, the most widely used combination was amoxicillin + clavulanic acid (hosp1:75\% ,hosp $2: 100 \%)$. This is the only combination that is used in both the hospitals. This was because of broad spectrum of activity and as per the recommendations by CDC. Another study conducted by Ashraf et al showed that the use of combination of amoxicillin + Clavulanic acid $40.74 \%$ was much lower than our study. ${ }^{6}$

In hospital 2, the drug that was widely used for respiratory diseases (LRTI, URTI) and fever was amoxicillin+clavulanic acid followed by ceftriaxone, cefotaxim and cefpodoxime. Whereas, amoxicillin+clavulanic acid followed by azithromycin, cefotaxime and cefixime was widely used in hospital 1 ( Table 8). In both the the hospitals ofloxacin was widely used for UTI.

In hospital 1 the total and average prescription cost was Rs 12,508.14 and Rs. 96.96; respectively. The total antibiotic cost was calculated as Rs. 5844.44 and the average antibiotic cost was Rs. 45.30 in hospital 1 whereas in hospital 2 the total and average prescription cost was Rs. 10,750.33 and Rs. 69.80 respectively. The total antibiotic cost was calculated as Rs 6495.85 and the average antibiotic cost as Rs. 39.60. This shows that the economic consideration is almost equal in both the hospitals. This is because the economic condition of the patients in this area was found to be low and hence the pediatricians have shown to prescribe drugs rationally thereby reducing the economic burden on the patients. A large variation is found in the average prescription cost and average antibiotic cost when compared to a similar 
study conducted by katta venkatesh et al. ${ }^{17}$ (The average total prescription cost and antibiotic cost was Rs. 106.66 and Rs. 70.32 (hospital 1), and Rs. 245.41and Rs. 113.32 (hospital 2), respectively).

\section{CONCLUSION}

The present study reveals that the most commonly prescribed antibiotic class in teaching and non teaching hospital were penicillins and cephalosporins. The most commonly prescribed antibiotic combination is amoxicillin + clavulanic acid (hospital1:75\%, hospital 2:100\%) in both the hospitals. The commonly diagnosed diseases in both the hospitals are URTI (hospital 1: 25.58\%, hospital 2: 20.12\%) and fever (hospital 1: 25.58\%, hospital 2: 22.72\%). In the teaching hospital average cost of prescription is Rs.96.96 and average antibiotic cost is Rs.45.30. In Non-teaching hospital average cost of prescription is Rs.69.80 and average antibiotic cost is Rs.39.60. The total number of drugs and the number of antibiotics prescribed were found to be rational in both the hospitals. However, more rationality was observed in non-teaching hospital with regard to prescribing pattern as well as economic criteria when compared to teaching hospital. Hence, the present study concludes that the prescribing pattern of antibiotics in the paedriatic outpatients of both the hospital is found to be rational according to guidelines.

\section{ACKNOWLEDGEMENT}

We would like to express our gratitude to everyone who was instrumental in this study. We sincerely thank Dr M.Rajshekar, Medical superintendent of NMCH and $\mathrm{RC}$, Raichur without whom this study would not have been possible.

\section{CONFLICT OF INTEREST}

No conflict of interest are declared.

\section{ABBREVIATION USED}

Amox: Amoxicillin; Amp: Ampicillin; Cef: Ceftriaxone; Cefo: Cefotaxim; Cefa: Cefadroxil; Cefi: Cefixime; Cefpo: Cefpodoxime; Cefu: Cefuroxime; Quino: Quinolones; Mac: Macrolides; Genta: Gentamicin; A+C: Amoxicillin+Clavulanicacid.

\section{REFERENCES}

1. Palikhe N. Prescribing Pattern of Antibiotics in Pediatric Hospital of Kathmandu Valley. Journal of Nepal Health Research Council.2004;2(2):31-6.

2. Choudhury DK, Bezbaruah BK. Antibiotic prescriptions pattern in paediatric Inpatient Department Gauhati Medical College and Hospital, Guwahati. J App Pharm Sci. 2013;3(8):144-8.

3. Sharma M, Eriksson B, Marrone G, Dhaneria S, Lund borg CS. Antibiotics prescribing in two private sector hospitals; one teaching and one nonteaching: Across sectional study in Ujjain, India. BMC infectious Disease. 2012;12(1): 155. http://dx.doi.org/10.1186/1471-2334-12-155; PMid:22788873 PMCid:PMC3447672.

4. Palikhe N. Prescribing Pattern of Antibiotics in Pediatric Hospital of Kathmandu Valley. Kathmandu University Medical Journal. 2004;2 (1):6-12.

5. Gupta N, Sharma D, Garg SK, Bhargava VK. Auditing of prescriptions to study utilization of antimicrobials in tertiary hospital. Ind J Pharmacol. 1997;29(6):4115.

6. Ashraf $\mathrm{H}$, Handa S, Khan NA. Prescribing pattern of drugs in outpatient department of child care centre in Moradabad city. International Journal of Pharmaceutical Sciences Review and Research. 2010;3(2):1-5.

7. Zhang L, Lovatel R, Nicolete D, Sinzkel E, Mateillo J, Staszko K, et al. Empiric antibiotic therapy in children with community acquired pneumonia. Ind Pediatr. 2008;45:554-8.

8. Arnold SR, Allen UD, Al-Zahrani M, Tan DH, Wang EE. Antibiotic prescribing by pediatricians for respiratory tract infection in children. Clin Infect Dis. 1999;29(2):312-7. http://dx.doi.org/10.1086/520207 ; PMid:10476734.

9. McCaig LF, Huges JM. Trends in antimicrobial drug prescribing among office-based physicians in the united states. JAMA. 1995;273(3):2149. http://dx.doi.org/10.1001/jama.273.3.214 : http://dx.doi.org/10.1001/ jama.1995.03520270048030.

10. Ramanath KV, Balaji B. Study the outpatients prescription pattern of antibiotics in paediatric populations of two hospitals. Arch Pharma Pract. 2013;4(1):21-7. http://dx.doi.org/10.4103/2045-080X.111578.

11. Venkateswaramurthy $\mathrm{N}$, Murali R, kumar SR. The study of drug utilization pattern in paediatricspatients. International Journal of Pharmacy and Pharmaceutical Sciences, 2013;5(3).

12. Kolar JV, Hromadova R. Analysis of antibiotic utilization in hospitalized paediatric patients. J Chin Clin Med. 2007;2:496-504.

13. Sunil KM, Sanjay S, Arun KS, ReenaM, Prescribing pattern of antimicrobials in pediatric outpatient department of tertiary care teaching hospital, ajmer (Rajasthan). International Journal of Pharmacology \& Toxicology Science.2013;3(4):40-6.

14. Mohan S, Dharamraj K, Dindial R, Mathur D, Parmasad V,Ramdhanie J, et al. Physician behaviour for antimicrobial prescribing for paediatric upper respiratory tract infections: A survey in general practice in Trinidad, West Indies. Ann Clin Micro boil Antimicrob. 2004;3(1):11. http://dx.doi.org/10.1186/14760711-3-11 ; PMid:15196306 PMCid:PMC441403.

15. Palcevski G, Ahel V, Viahovic-Palveski V, RatchinaS,Rosovic-Bazijanac V, Averchenkova L. Antibiotic use profile at paediatric clinics in two transitional countries.Pharmacoepidomol Drug Saf. 2004;13(3):181-5. http://dx.doi. org/10.1002/pds.880 ; PMid:15072118.

16. Sharma R, Chopra VS, Kour G. Use of antibiotics for respiratory illnesses in rural India J ClinDiagn Res. 2009;3:1557-61.

17. Katta VR, Balaji BVB, Study the outpatients prescription pattern ofantibiotics in paediatric populations of two hospitals.Archives of Pharmacy Practice. 2013;4(1):21-27. http://dx.doi.org/10.4103/2045-080X.111578. 